\title{
Subtypes of Family History and Conduct Disorder: Effects on P300 During the Stroop Test
}

Lance O. Bauer, Ph.D., and Victor M. Hesselbrock, Ph.D.

The goal of the present study was to identify neurophysiological differences associated with a family history of substance dependence, and its subtypes (paternal alcohol, cocaine, or opiate dependence), and with conduct disorder, and its subtypes (aggression, deceitfulness/theft, and rules violations). P300 event-related brain potentials were recorded from 210 males and females, aged 15-20 years while they performed the Stroop color-word compatibility test. Analyses revealed no significant effects of familial substance dependence on P300. However, an elevated number of conduct disorder problems was associated with a statistically significant reduction in P300 amplitude. The P300 amplitude reduction was related to the severity of the "rules violation" subtype, but was unrelated to aggression or deceitfulness and theft. It is concluded that conduct disorder can explain many of the P300 findings previously attributed to a family history of alcohol dependence. Furthermore, it appears that conduct disorder may be a heterogenous classification comprised of neurophysiologically different subtypes.

[Neuropsychopharmacology 21:51-62, 1999] (C) 1999 American College of Neuropsychopharmacology. Published by Elsevier Science Inc.
KEY WORDS: Substance-related disorders; Alcoholism; Hereditary diseases; Conduct disorder; Antisocial personality disorder; Evoked potentials; EEG

In the standard Stroop Test [Stroop (1935); see MacLeod (1991) for a review], subjects are instructed to name the color in which a word is typed and ignore the meaning of the word itself. Despite this instruction, word meaning has been found to reliably influence the latency of the color-naming response. The most thoroughly documented finding from studies of the Stroop Test is an increase in color-naming latency when the word and

From the Department of Psychiatry, University of Connecticut School of Medicine, Farmington, CT.

Address correspondence to: Dr. Lance Bauer, Department of Psychiatry, MC 1203, University of Connecticut Health Center, Farmington, CT 06030.

Received August 17, 1998; revised December 2, 1998; accepted December 3, 1998. color are incompatible (e.g., the word "red" presented in blue typeface). Using a more modern version of the test, it is also possible to demonstrate a decrease in naming latency when the word and color are compatible (e.g., the word "red" presented in red typeface), relative to a condition in which they are unrelated (e.g., the word "town" in red typeface). The Stroop Test can therefore be used to assess cognitive operations that inhibit and/or facilitate response selection.

Many versions of the Stroop Test have been developed over the past 63 years. Despite these variations in methodology, the findings have been remarkably consistent (Siegrist 1995, 1997). For example, the same pattern of results occurs as described above when naming latency is replaced by naming accuracy as the dependent measure, or when vocal naming is replaced by a choice key press as the required response. Also, the additional constraints associated with implementing the test in the context of either an electroencephalographic 
(EEG) (Duncan-Johnson and Kopell 1981) or positron emission tomographic (PET) (Bench 1993; Posner and Driver 1992; Pardo et al. 1990) study do not alter the Stroop effect. Indeed, EEG and PET studies have proven quite useful in investigating the neural substrates activated by the test.

The goal of the present study was to examine response inhibition and response facilitation during the Stroop Test among groups of teen-aged subjects characterized by a hypothesized dysfunction in response regulation. These groups included teenagers who were the biological offspring of alcohol- or drug-dependent fathers, as well as teenagers who exhibited conduct problems of sufficient magnitude as to approach or meet the DSM-IIIR criterion for conduct disorder. Subjects possessing these familial and personal risk factors for future alcohol/drug dependence have previously been shown to perform poorly on the Stroop Test, Wisconsin Card Sorting Test, Porteus Maze, Trails B, LuriaNebraska Motor Alternation, and other neuropsychological tests that are presumed to measure cognitive flexibility and/or response regulation (Hesselbrock et al. 1991; Gillen and Hesselbrock 1992; Moffitt 1993; Lahey et al. 1993). However, it is presently unknown whether there are subtypes of conduct disorder (e.g., characterized by higher levels of aggression vs. deceitfulness and theft vs. rules violations) or family history (e.g., paternal alcohol vs. cocaine vs. heroin dependence) that are more reliably associated with these neuropsychological decrements. A secondary goal of this study was to examine the effects of such subtypes.

As in our previous studies of conduct disorder and family history, the present study included an assessment of P300 event-related electroencephalographic potentials (ERP). A number of studies conducted by our group have demonstrated P300 amplitude reductions among adults and teenagers diagnosed with either Antisocial Personality Disorder (Bauer 1997; Bauer et al. 1994a, 1994b; O'Connor et al. 1994) or with elevated counts of Conduct Disorder criterion behaviors (Bauer and Hesselbrock in press), respectively. The P300 decrements were largest over frontal brain regions (Bauer 1997; Bauer et al. 1994a, 1994b) and correlated significantly with poor performance on "frontal" neuropsychological tests (Hesselbrock et al. 1993). A number of ERP studies have also linked P300 amplitude reductions to a family history of alcoholism (Begleiter et al. 1984; Elmasian et al. 1982; Whipple et al. 1988; see Polich et al. 1994 for a review). However, the P300 effects of a family history of alcohol/drug dependence appear to be negligible when its overlap with conduct disorder/ASPD is considered (Bauer and Hesselbrock in press).

To our knowledge, only one study has examined P300 while subjects performed the Stroop Test (Duncan-Johnson and Kopell 1981). In that study, ERP data were collected from 12 male college students without psychopathology or significant histories of drug abuse. The results revealed no change in P300 latency on incompatible versus compatible stimulus trials. P300 amplitude was not examined. The absence of a change in P300 as a function of color-word incompatibility was used by the authors as a basis for claiming that P300 is unaffected by processes related to response selection. More recent studies of stimulus-response compatibility manipulations have revealed this conclusion to be incorrect. In normal subjects, P300 amplitude and latency do indeed change when the demands on response selection are increased (Christensen et al. 1996; Renault et al. 1988; Pfefferbaum et al. 1986; Valle-Inclán 1996). To date, no investigator has recorded P300 from adolescents with risk factors for alcoholism or drug abuse while they perform the Stroop Test.

\section{METHODS}

\section{Subjects}

The subjects were 210 males and females, 15 to 20 years old, assigned to groups on the basis of a positive or negative history of DSM-IIIR opiate, cocaine, or alcohol dependence in their biological father, and a positive or negative personal history of conduct disorder problems.

The primary source for identifying potential subjects with a positive family history was their drug- or alcohol-dependent fathers. Fathers were recruited at local drug abuse treatment facilities. Additional sources for recruiting both positive family history and all other types of subjects included newspaper and radio advertisements that appealed to either prospective subjects or their parents. The sources included high school guidance counselors, youth organizations (YMCA, YWCA, Police Athletic League, etc.), and newspaper and radio advertisements. Importantly, none of the teenagers studied presently were recruited from detention or treatment programs. Accordingly, the level of comorbid psychopathology and drug abuse was not significant.

Before data collection could begin, the parent and teen-aged child provided written, informed consent. Fathers were interviewed about their history of drug and alcohol use, psychiatric problems, and neurological disorders. Whenever possible, the biological mother was also interviewed. In those cases $(25.7 \%)$ in which the father was unwilling or unable to participate, the mother served as a proxy source for information about the father.

To eliminate the possible confounding effects of fetal alcohol/drug exposure, children whose biological mothers met lifetime DSM-IIIR criteria for diagnosis of alcohol, cocaine, or opiate dependence were excluded. Teenagers were also excluded if they had a history of schizophrenia, bipolar or major depressive disorder, 
DSM-IIIR drug (including alcohol) abuse or dependence, neurological or endocrine disorders, significant head injury (e.g., loss of consciousness greater than 5 minutes), an uncorrected visual acuity of greater than $20 / 50$, or color blindness. Use of CNS active medications either led to the exclusion of the subject or to a delay in the scheduled appointment until medications were no longer being taken. Urine and breath samples were collected on the test day to verify abstinence.

A complete and detailed lifetime psychiatric history was obtained from each teenaged subject and at least one parent via the Semi-Structured Assessment for the Genetics of Alcoholism (SSAGA) (Bucholz et al. 1994). The SSAGA interview covers the major psychiatric disorders defined in the DSM, ICD, and Feighner systems and has been shown to have good reliability. For the present study, DSM-IIIR criteria were applied. The SSAGA interview was conducted by a trained technician. The interview was also tape-recorded to monitor the reliability of the assessment procedure.

The psychiatric status of all first and second degree biological relatives was obtained from subjects and the parent(s) using the family history method (FHAM) (Rice et al. 1995). The family histories (FH) of subjects were categorized as none (FHN), alcohol-dependent (FHA), cocaine-dependent (FHC), or opiate-dependent (FHO) based upon the primary clinical diagnosis of the biological father. Subjects in the FHN group had no known first- or second-degree relatives affected with alcohol or other substance dependence.

The assignment of a subject to one of the two conduct disorder behavior groups was based on the median number of DSM-IIIR conduct disorder (CD) criterion items met prior to age 15 (cf. Fergusson and Horwood 1995; Slutske et al. 1997). As required by DSM-IIIR, a criterion item was counted only if the behavior occurred at or above the required frequency (typically on multiple occassions) over a period of 6 months. Separate calculations were performed for males and females. For males, the cutpoint for differentiating $\mathrm{CD}-/ \mathrm{CD}+$ groups was two or more criterion items. For females, the cutpoint was one or more criterion items.

For secondary analyses of subtypes of conduct disorder, subjects were assigned to low (i.e., none), moderate, and higher severity groups using counts of 0,1 , or $\geqslant 2$, respectively, from the aggression, rules violation, and deceitfulness/theft subsets of the diagnostic criteria for $C D$. There was inadequate variability in the number of destructiveness criterion items to justify the creation of a destructiveness scale. Because many subjects with CD problems scored highly on all subscales, it was impossible to examine interactions among subtypes or the unique effects of each subtype. Rather, the analyses of each $C D$ problem subscale included the same subjects regrouped in a different manner. Gender was a separate independent variable in these analyses.

\section{Procedure}

EEG data collection occurred on the same day scheduled for the collection of all other data. Tests of sensory function (color vision, visual acuity) were administered early in the day to identify factors which would artifactually impair performance on the Stroop Test. Access to caffeinated beverages and nicotine were denied throughout the day.

The subject was escorted into a sound-shielded chamber and seated in a comfortable chair, where EEG and EOG electrodes were applied. The chair faced a 14inch computer monitor used for the presentation of visual stimuli. A set of shielded stereo headphones, used for auditory stimulus presentation, and other devices (response keys), were located in the immediate proximity of the chair.

Subjects performed a discreet trials version of the Stroop Test in which the stimuli were the words RED, BLUE, or TOWN presented in red or blue typeface on the computer monitor. There were, therefore, three categories of stimuli (100 trials/category): incompatible, compatible, and unrelated. The stimuli were presented with equal probability at a rate of one stimulus every 2.3 seconds for $100 \mathrm{msec}$ each. Subjects were asked to indicate the color of the word by pressing one of two response keys within a response deadline of $1000 \mathrm{msec}$. Before data collection began, subjects were required to practice the task and demonstrate comprehension of task instructions.

\section{EEG Recording Procedures and Analysis}

The EEG was recorded from tin electrodes placed at 31 scalp sites (ECI Incorporated, Eaton, $\mathrm{OH}$ ). A single tin electrode placed on the bridge of the subject's nose served as the reference. A mid-forehead electrode served as the ground. For the detection of eye blink and eye movement artifacts, a pair of tin electrodes was placed diagonally above and below the left eye. Interelectrode impedances were kept below $5 \mathrm{~K}$.

The 31 channels of EEG activity and one channel of eye movement activity were appropriately amplified $(\mathrm{EEG}$ gain $=20 \mathrm{~K}$, EOG gain $=2 \mathrm{~K})$ and filtered (Bandpass $=0.01$ to $30 \mathrm{~Hz}$ ) using a Grass Instrument Company Neurodata Acquisition System (Model 12). Along with voltage markers used to indicate the onset of significant experimental events (stimulus and response triggers), the EEG and EOG channels were routed to an A-to-D converter, sampled at a rate of $500 \mathrm{~Hz}$ for 100 msec preceeding and $900 \mathrm{msec}$ following stimulus onset, and stored for offline analysis. Each sampling epoch was digitally filtered and tested for the presence of A-to-D converter overflow as well as for excessive voltage changes $(>100 \mu \mathrm{V})$ in the EEG associated with lead sway or other movement artifacts. A positive test for ei- 
ther condition resulted in the exclusion of all data for that epoch. Eye blinks and other eye movement artifacts were removed from the EEG using the algorithm described by Semlitsch et al. (1986). The processed EEG epochs on correct response trials were then sorted by lead and stimulus type and averaged. P300 was identified as the peak voltage, with a zero slope, in the averaged ERP waveform between 250 and $900 \mathrm{msec}$ following stimulus onset. Amplitude was expressed in microvolts relative to the average voltage druing the $100-\mathrm{msec}$ prestimulus period. Latency was expressed in msec relative to stimulus onset.

To reduce the number of independent analyses performed on inter-related P300 data and the overall probability of Type I error, a principal components analysis (PCA) was employed. The inputs to the six (amplitude + latency $\times 3$ trial categories) separate PCAs were the correlation matrices of either P300 amplitude or latency measured at each of the 31 electrode locations for each stimulus category (compatible, incompatible, unrelated). Through these PCAs, scalp regions containing intercorrelated activity were identified and separated into coherent units by orthogonal rotation. Each functionally distinct region was analyzed separately.

The six PCAs yielded identical results consisting of two orthogonal factors. The electrode locations loading highest on the first factor included 17 locations adjacent or posterior to the central sulcus: $\mathrm{C} 3, \mathrm{CP} 1, \mathrm{C} 4, \mathrm{CP} 2, \mathrm{Pz}$, P3, PO1, P4, PO2, CP5, T7, CP6, T8, P7, P8, O1, and O2. The second factor included the remaining, frontal locations: F3, FC1, F4, FC2, F7, FC5, F8, FC6, FP1, AF1, FP2, $\mathrm{AF} 2, \mathrm{Fz}$, and $\mathrm{Cz}$.

P300 amplitudes and latencies from these posterior and anterior regions were analyzed separately via repeated measures analysis of variance. Within each analysis, Conduct Disorder group, Family History group, or Gender were entered as between-subjects factors (for a detailed description, see below). Electrode Location and Trial Category (compatible/incompatible/unrelated) were within-subjects factors. Where appropriate, the Geisser-Greenhouse formula was applied to protect against violations of the sphericity assumption. Corrected degrees of freedom are reported.

\section{RESULTS}

\section{FH Subtype $\times$ Conduct Disorder Analyses}

Demographic, Drug Use, and Psychiatric Characteristics. Table 1 summarizes the background characteristics of subjects assigned to each of the eight groups within the $\mathrm{FH} \times \mathrm{CD}$ factorial. Group differences were evaluated using two-way ANOVAs for continuous measures and Pearson's $\chi^{2}$ tests for categorical measures.

Differences among the groups on these background variables were generally modest or nonsignificant. There was a slight, but significant, difference among the FH groups in age and in years of education: teenagers born to cocaine-dependent fathers were 1 year younger and had completed 1 less year of school than teenagers born to fathers without an alcohol or drug abuse history. Importantly, age did not correlate with any of the group differences in P300 amplitude that are reported below $(r=0.018, p=\mathrm{ns})$.

There was a relative and more reliable difference between the $\mathrm{CD}+(3.84 \pm 6.54)$ and $\mathrm{CD}-(1.57 \pm 3.64)$ groups in the number of alcohol use problems reported on the MAST. The absolute number of alcohol use problems in the $\mathrm{CD}+$ group was modest, however.

There were no significant differences among the groups in gender or ethnic composition; in the proportion of subjects meeting criteria for the combined, inattentive, or hyperactive-impulsive subtypes of Attention Deficit-Hyperactivity Disorder (which was uniformly rare, viz. $<3 \%$ ); or in the proportion of subjects whose paternal alcohol/drug use history was based on the results of a proxy interview with the mother.

Table 1. Demographic, Drug Use, and Psychiatric Characteristics (Mean (SD) or \%)

\begin{tabular}{|c|c|c|c|c|c|c|c|c|}
\hline Variable & $\begin{array}{c}\text { FHN } \\
\text { CD- } \\
(n=54)\end{array}$ & $\begin{array}{c}\text { FHA } \\
\text { CD- } \\
(n=27)\end{array}$ & $\begin{array}{c}\text { FHC } \\
\text { CD- } \\
(n=17)\end{array}$ & $\begin{array}{c}\text { FHO } \\
\text { CD- } \\
(n=17)\end{array}$ & $\begin{array}{c}\text { FHN } \\
\text { CD+ } \\
(n=26)\end{array}$ & $\begin{array}{c}\text { FHA } \\
\text { CD+ } \\
(n=35)\end{array}$ & $\begin{array}{c}\text { FHC } \\
\text { CD+ } \\
(n=24)\end{array}$ & $\begin{array}{c}\text { FHO } \\
\text { CD+ } \\
(n=10)\end{array}$ \\
\hline Years of education ${ }^{a}$ & $10.7(1.6)$ & $9.7(1.5)$ & $9.5(1.3)$ & $10(1.7)$ & $10.2(1.2)$ & $10.2(1.5)$ & $9.4(1.5)$ & $9.1(1.1)$ \\
\hline Years of age $\mathrm{e}^{b}$ & $16.9(1.5)$ & $16(1.8)$ & $15.7(1.4)$ & $16(1.3)$ & $16.7(1.3)$ & $16.8(1.5)$ & $15.9(1.3)$ & $16.2(1.5)$ \\
\hline MAST score ${ }^{c}$ & $1.8(4.4)$ & $1.5(2.9)$ & $1(1.5)$ & $1(2.3)$ & $3.2(5.2)$ & $5.1(8.5)$ & $2.6(4.1)$ & $3.4(5.2)$ \\
\hline Female (\%) & 64.2 & 51.9 & 50 & 75 & 57.7 & 37.1 & 54.2 & 40 \\
\hline Caucasian (\%) & 67.9 & 85.2 & 35.7 & 56.3 & 34.6 & 71.4 & 29.2 & 40 \\
\hline $\begin{array}{c}\text { Paternal history determined by proxy } \\
\text { interview of mother }(\%)\end{array}$ & 16.7 & 29.6 & 29.4 & 11.8 & 38.5 & 42.9 & 16.7 & 10 \\
\hline
\end{tabular}

${ }^{a}$ FH Main Effect, $p<.05$, [FHC and FHO] $<$ FHN.

${ }^{b}$ FH Main Effect, $p<.05$, FHC $<$ FHN.

${ }^{c}$ CD Main Effect, $p<.05, \mathrm{CD}+>\mathrm{CD}-$. 


\section{DEMONSTRATIONS OF STROOP \\ INHIBITION AND FACILITATION}
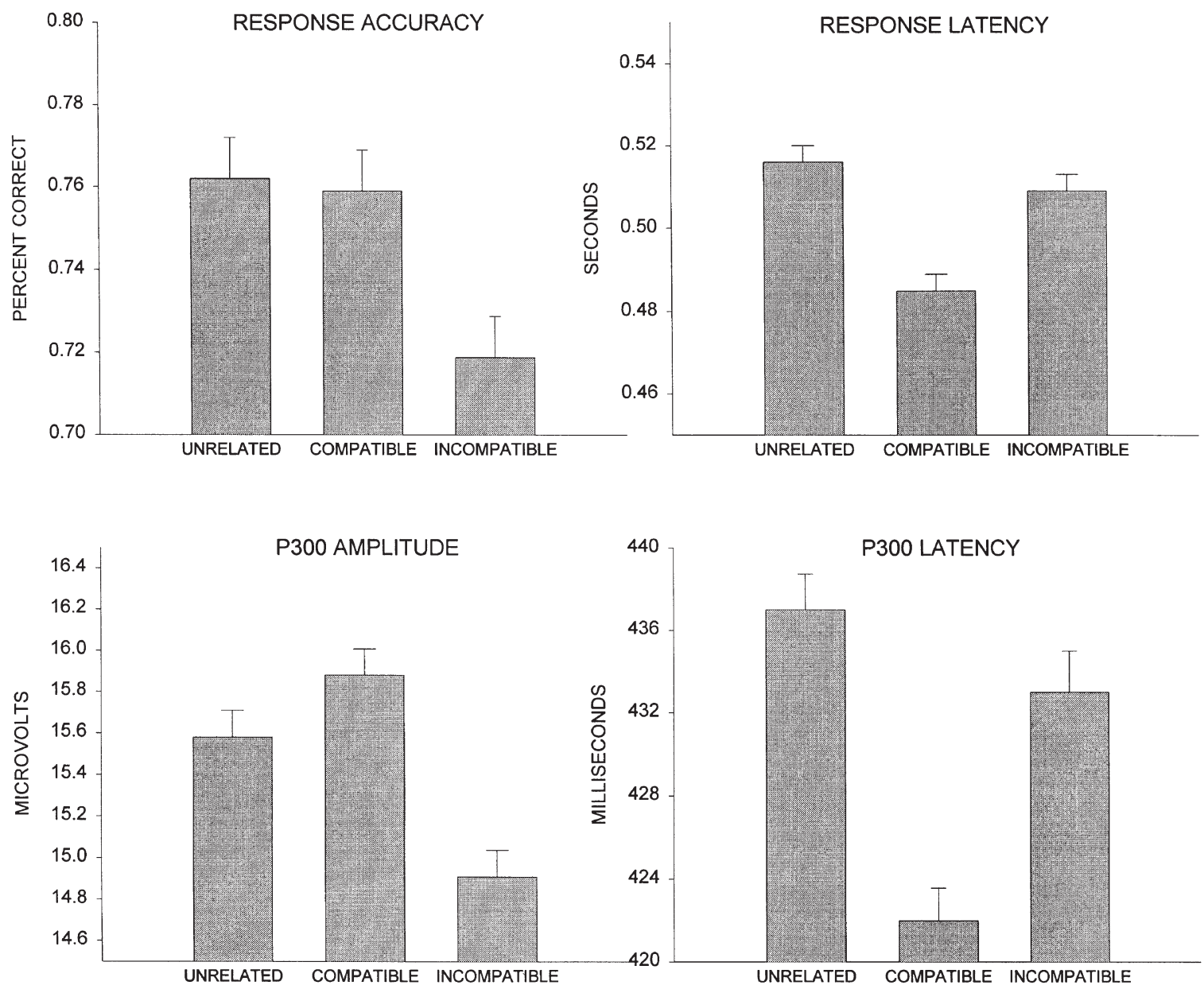

Figure 1. Average (+1 SEM) response accuracy and latency, and posterior region P300 amplitude and latency, for unrelated, compatible, and incompatible color-word combinations.

Test Performance. Figure 1 illustrates the significant effects of trial category on response latency $\left(\mathrm{F}_{2,390}=\right.$ $62.3, p<.0001)$ and accuracy $\left(\mathrm{F}_{2,397}=63.0, p<.0001\right)$. In these three-way ANOVAs of Trial Category $\times \mathrm{CD} \times$ $\mathrm{FH}$, there were no significant main or interactive effects involving $\mathrm{CD}$ or $\mathrm{FH}$.

Tukey post hoc tests evaluating the Trial Category main effects revealed a significant reduction in re- sponse accuracy on incompatible as compared to both compatible and unrelated trials. There were no differences between compatible and unrelated trials in response accuracy, but these trials were associated with a significant difference in response latency (compatible $<$ unrelated). Response latency also differentiated compatible and incompatible trials, in the predicted direction (compatible $<$ incompatible).

Table 2. Posterior Region P300 Amplitude (SD) by Subject Group

\begin{tabular}{lcccccccc}
\hline Variable & $\begin{array}{l}\text { FHN } \\
\text { CD }-\end{array}$ & $\begin{array}{l}\text { FHA } \\
\text { CD }-\end{array}$ & $\begin{array}{c}\text { FHC } \\
\text { CD }-\end{array}$ & $\begin{array}{c}\text { FHO } \\
\text { CD }-\end{array}$ & $\begin{array}{c}\text { FHN } \\
\text { CD }+\end{array}$ & $\begin{array}{c}\text { FHA } \\
\text { CD }+\end{array}$ & $\begin{array}{c}\text { FHC } \\
\text { CD }+\end{array}$ & $\begin{array}{l}\text { FHO } \\
\text { CD }+\end{array}$ \\
\hline P300 Amplitude $^{a}$ & $16.1(6.9)$ & $16.8(7.4)$ & $15.2(6.9)$ & $17.5(7.4)$ & $14.1(7.0)$ & $15.0(6.5)$ & $13.9(6.0)$ & $13.5(6.6)$ \\
\hline
\end{tabular}

${ }^{a}$ CD Main Effect, $p<.05$. 


\section{COMPATIBLE COLOR-WORD COMBINATIONS ERPS AT PZ ELECTRODE AVERAGED BY FAMILY HISTORY GROUP}

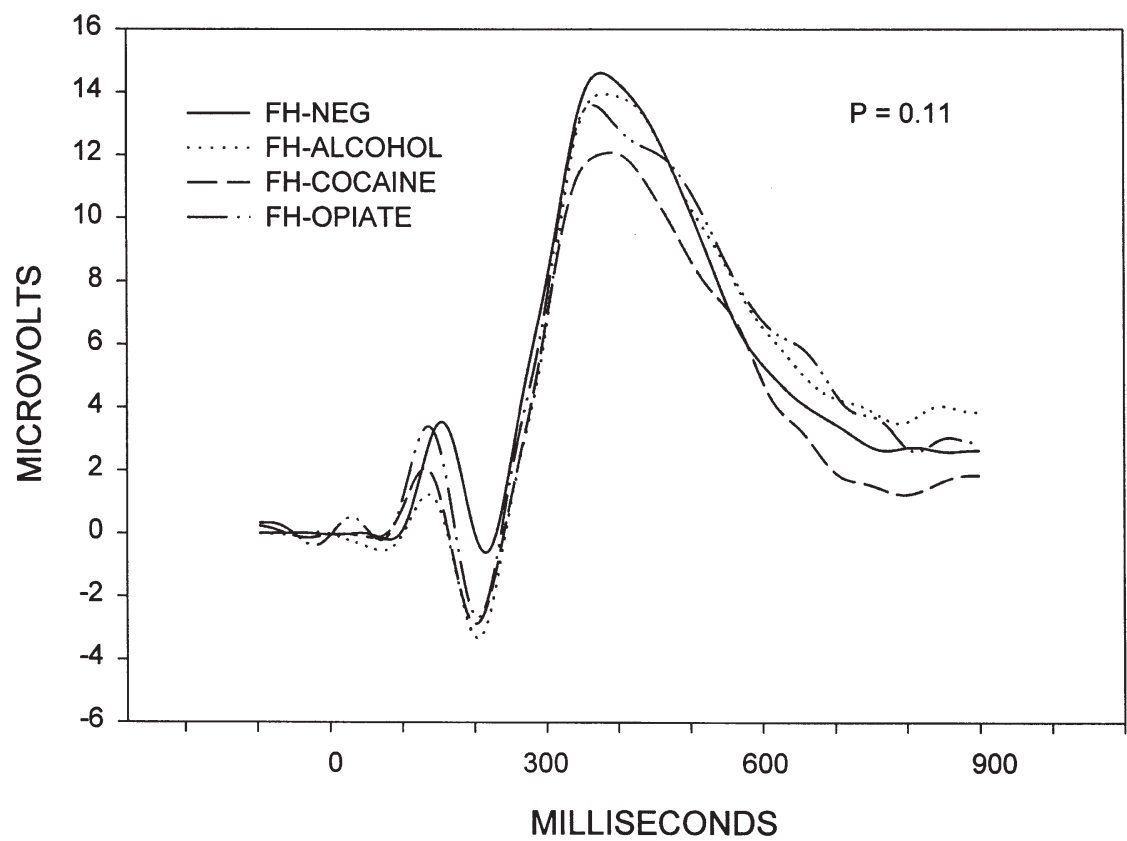

\section{INCOMPATIBLE COLOR-WORD COMBINATIONS ERPs AT PZ ELECTRODE AVERAGED BY FAMILY HISTORY GROUP}

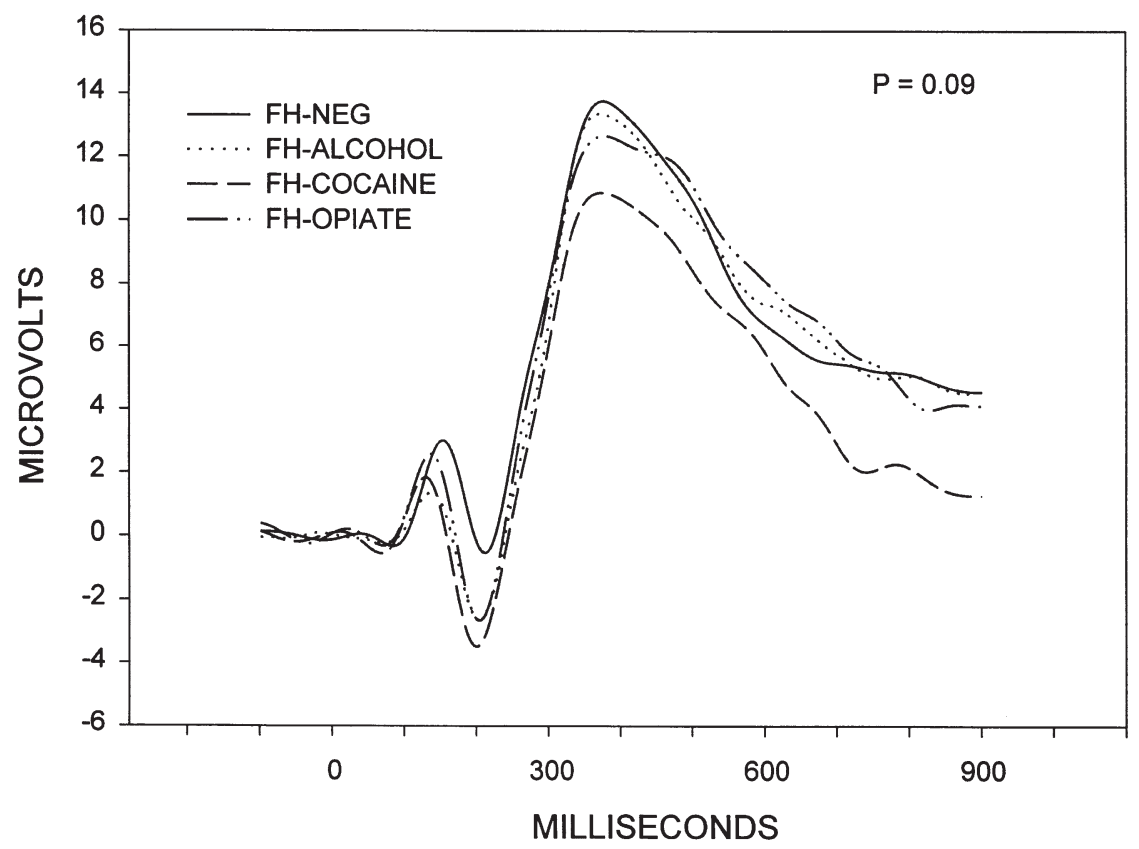

Figure 2. ERPs recorded from the $\mathrm{Pz}$ electrode for compatible (top) and incompatible (bottom) trials. The data are averaged separately for each family history group (and are collapsed over the levels of the Conduct Disorder variable). The differences among the family history groups in P300 amplitude were not significant. Waveform polarity $=$ positive up. $\mathrm{X}$-axis scale $=\mathrm{msec}$ relative to stimulus onset.
P300 Data. Analyses of P300 amplitude and latency revealed significant effects of Trial Category over both posterior and anterior scalp regions. Over the posterior region, incompatible trials evoked a smaller amplitude P300 than compatible trials $\left(\mathrm{F}_{2,399}=7, p<.001\right)$. P300 latency was found to be shorter on compatible versus incompatible and unrelated trials $\left(\mathrm{F}_{2,395}=4.04, p<.02\right)$. Similar results were found in the analysis of P300 amplitude $\left(\mathrm{F}_{2,403}=6.8, p<.001\right)$ and latency $\left(\mathrm{F}_{2,398}=3.8\right.$, $p<.03)$ over the anterior region. The effects of Trial Category on posterior region P300 amplitude and latency are illustrated in Figure 1. 
Trial Category did not interact with $\mathrm{FH}$ subtype, CD, or Electrode Location. The only significant finding involving the between-subjects factors was a main effect of $\mathrm{CD}\left(\mathrm{F}_{1,202}=6.9, p<.01 ; \mathrm{M}_{\mathrm{CD}}-=16.36 \pm 7.1 \mu \mathrm{V}\right.$; $\left.\mathrm{M}_{\mathrm{CD}}+=14.36 \pm 6.5 \mu \mathrm{V}\right)$ on P300 amplitude within the posterior region only. Table 2 provides a list of groupaveraged P300 amplitudes and standard deviations for each of the eight subject groups. Figure 2 demonstrates the absence of a significant main effect of FH on P300 at the Pz electrode.

\section{Conduct Disorder Subtype $\times$ Gender Analyses}

Demographic, Drug Use, and Psychiatric Characteristics. ANOVAs of the independent and interactive effects of each subtype of conduct disorder (aggressive, deceitful, rules violation) and gender revealed a significant main effect (i.e., $p<.05$ ) of each of the $C D$ subtypes on MAST scores. In all three analyses, higher levels of personality dysfunction were associated with higher scores (i.e., more alcohol use problems): $\mathrm{M}_{\text {aggression (low } \rightarrow \text { high) }}=2.4 \pm 5.2 \rightarrow 2.6 \pm 5.4 \rightarrow 4.1 \pm 6.3$; $\mathrm{M}_{\text {deceitfulness (low } \rightarrow \text { high) }}=1.9 \pm 5.1 \rightarrow 2.6 \pm 3.7 \rightarrow 7.4 \pm 7.7$; $\mathrm{M}_{\text {rules violation }(\mathrm{low} \rightarrow \text { high })}=1.2 \pm 3.6 \rightarrow 1.9 \pm 2.9 \rightarrow 5.1 \pm$ 7.5. There were no gender differences in MAST scores, age, or educational level. There were also no Gender $\times$ CD subtype interactions.

Test Performance. Analyses of response latency and accuracy yielded the same significant effects of Trial Category as described above. There were no differences among the $\mathrm{CD}$ subtypes in test performance. However, the analyses of response latency revealed a significant main effect of Gender $\left(\mathrm{F}_{1,198}=8.79, p<.004\right)$. Overall, males responded $26 \mathrm{msec}$ faster than females. The gender difference did not vary with CD subtype or Trial Category.

P300 Data. To limit the number of analyses performed and the attendant risk of Type I error, the analyses of P300 focused only on the posterior region, which had revealed a main effect of $C D$ in prior analyses. The effects of Trial Category on P300 amplitude and latency in these analyses were identical to those described above. Gender was found to have no significant effect, although there was a trend for males to have smaller P300 amplitudes than females. There was also a nonsignificant trend for shorter P300 latencies in males versus females.

The only CD subtype to affect P300 was the Rules Violations factor. Higher levels of severity on this factor were associated with a graded reduction in P300 amplitude $\left(\mathrm{F}_{2,198}=8.2, p<.005\right)$ ranging from $16.8 \pm 7.5$ to $14.9 \pm 6.3$ to $14.4 \pm 6.6 \mu \mathrm{V}$. None of the CD subtypes interacted significantly with Gender or Trial Category. However, there was a trend suggesting a stronger or more reliable effect of the Rules Violation subtype on incompatible versus compatible trials (compare bottom right panels of Figures 3 and 4).

Averaged ERP waveforms at the $\mathrm{Fz}, \mathrm{Cz}$, and Pz electrodes depicting the effects of conduct disorder and the three conduct disorder subtypes are presented in Figures 3 and 4 .

\section{DISCUSSION}

In the present study, manipulations of color-word compatibility yielded evidence of both response inhibition and response facilitation. When the color-word combination was incompatible, response accuracy declined relative to accuracy for both compatible and unrelated combinations. This finding is consistent with response inhibition. However, contrary to the classic Stroop inhibition effect, there was no attendant increase in response latency. We attribute the absence of a change in response latency on incompatible trials to the use of a 1000-msec response deadline, which probably truncated the variance in reaction time and forced late responses to be counted as errors. This hypothesis is reinforced by the demonstration of enhanced error rates on incompatible trials. Response latency did demonstrate Stroop facilitation: responses occurred more quickly when the color-word combination was compatible versus a condition in which they were unrelated.

Analyses of P300 also provided evidence of Stroop inhibition and facilitation. The inhibition of P300 amplitude resembled the inhibition of response accuracy. Both of these dependent measures varied similarly on incompatible trials but were unchanged on compatible trials (see Figure 1, left panel). The changes in P300 latency resembled the changes in response latency. Both were facilitated by color-word compatibility and not inhibited by color-word incompatibility (see Figure 1, right panel). The present demonstration of significant effects of color-word compatibility and incompatibility on P300 is consistent with the results of studies using cognitive tests similar to that used presently (e.g., Christensen et al. 1996; Renault et al. 1988; Pfefferbaum et al. 1986; Valle-Inclán 1996). However, the results of the present study do contradict the results of one previous study that failed to detect an effect of the Stroop Test on P300 (Duncan-Johnson and Kopell 1981). The null findings reported by Duncan-Johnson and Kopell (1981) are most likely attributable to the small number of subjects tested $(n=12)$ in their study and inadequate statistical power.

Interestingly, teenagers with conduct disorder problems did not differ significantly from teenagers without conduct problems in the magnitude of either Stroop inhibition or facilitation. The P300 decrement associated with conduct problems was of the same magnitude on 
unrelated, compatible, and incompatible trials. One interpretation of this pattern of results suggests that the cognitive deficit associated with CD might not be specifically tied to response inhibition/facilitation in teen- aged subjects. Rather, the deficit may involve a more generalized disturbance of attention or resource allocation. Another interpretation suggests that an interaction between $\mathrm{CD}$ and Stroop inhibition/facilition would

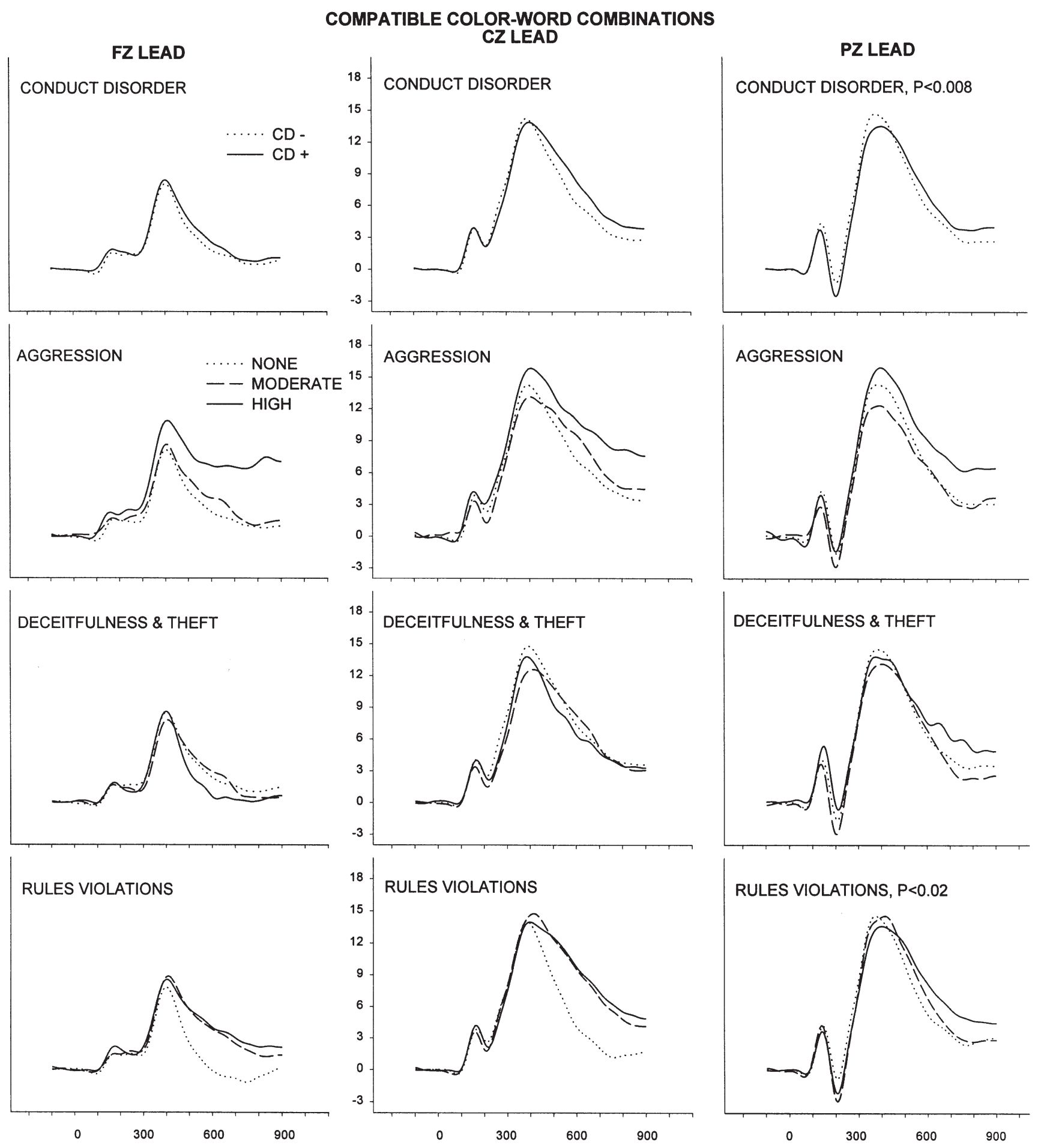

Figure 3. ERPs at Fz, Cz, and Pz electrodes evoked by compatible color-word combinations. ERPs represent group-averaged data for analyses comparing CD- (dotted line) versus CD+ (solid line) groups, as well as for analyses comparing low (dotted line), moderate (dashed line), and higher (solid line) scores on the aggression, deceitfulness/theft, and rules violations subsets of the CD diagnostic criteria. Waveform polarity $=$ positive up. X-axis scale $=$ msec relative to stimulus onset. 
have attained significance if the subject sample had contained more individuals with a severe form of CD.

One more factor to consider in the interpretation of the effects of CD on P300 is the age of the subjects tested in the present study. In neuroimaging (i.e., PET) studies of the Stroop Test, incompatible trials have been shown to evoke activity in selected frontal brain regions, such as the anterior cingulate (Bench 1993; Pardo et al. 1990; Posner and Driver 1992), in healthy adults. It is possible that the power for detecting an interaction between

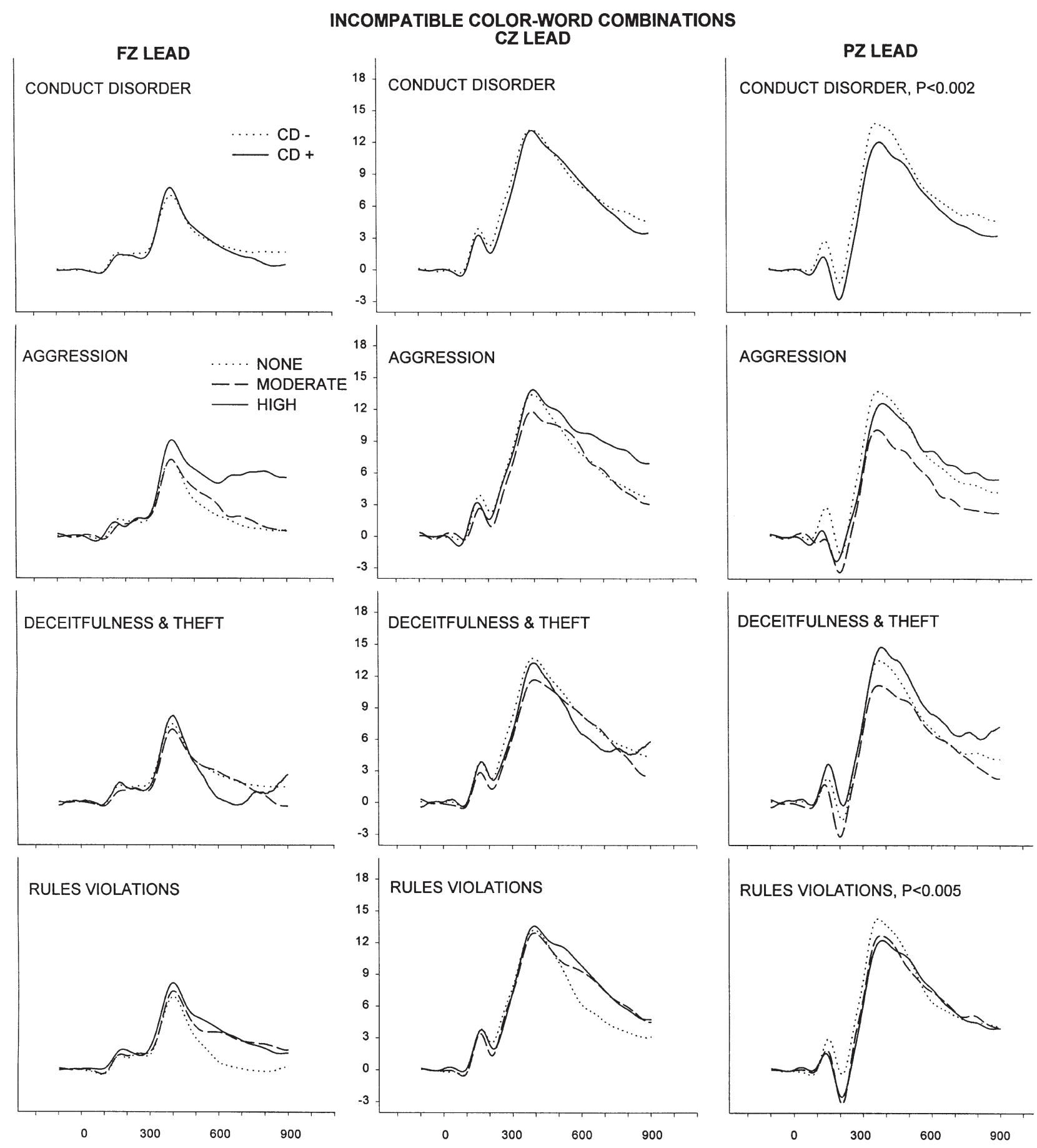

Figure 4. ERPs at $\mathrm{Fz}, \mathrm{Cz}$, and Pz electrodes evoked by incompatible color-word combinations. ERPs represent group-averaged data for analyses comparing $C D-$ (dotted line) versus $C D+$ (solid line) groups, as well as for analyses comparing low (dotted line), moderate (dashed line), and higher (solid line) scores on the aggression, deceitfulness/theft, and rules violations subsets of the CD diagnostic criteria. Waveform polarity $=$ positive up. X-axis scale $=$ msec relative to stimulus onset. 
$\mathrm{CD}$ and Stroop inhibition was inadequate in the present study because of substantial variability in the developmental status of these frontal neural substrate(s) in both $\mathrm{CD}-$ and $\mathrm{CD}+$ subjects. An implication of this hypothesis is that it may be easier to demonstrate an interaction between a history of childhood CD (and its adult analogue-ASPD) and Stroop inhibition/facilitation in adults than in adolescents. Indeed, recent studies using a mental rotation task have revealed that frontal P300 decrements are less apparent in conduct-disordered adolescents (Bauer and Hesselbrock in press) than in ASPD+ adults (O'Connor et al. 1994). Furthermore, the P300 decrements associated with CD in Bauer and Hesselbrock's study shifted from a posterior focus during mid-adolescence to a frontal focus in early adulthood.

An important contribution of the present study is the demonstration that some subtypes of $\mathrm{CD}$ have a more reliable effect on P300 than other subtypes. Teenagers who exhibited a behavior pattern characterized by repeated, serious violations of rules (i.e., truancy, running away from home, "staying out" at night) exhibited significant reductions in P300 amplitude. However, teenagers with aggressive features or with a history of deceitfulness and theft did not exhibit these reductions. Admittedly, the subjects studied here were not recruited from detention or treatment programs and may not be ideal for revealing the neurophysiological correlates of either aggression, deceitfulness, or theft. A conservative interpretation of the present findings would suggest that only the most benign form of conduct disorder, viz., rules violations, was sufficiently severe in this sample as to be reflected neurophysiologically. Whether aggressive and deceitfulness/theft subtypes of conduct disorder are associated with an additional, or perhaps unique, neurophysiological decrement remains to be determined (cf. Herning et al. 1989; Pickworth et al. 1990) from studies of subject populations that manifest more serious/severe forms of these behaviors.

The present study did not reveal evidence of reductions in P300 amplitude associated with a family history of alcohol, cocaine, or opiate dependence (see Table 2). Although several studies have demonstrated an effect of familial alcoholism on P300 [Begleiter et al. 1984; Elmasian et al. 1982; Whipple et al. 1988; see Polich et al. (1994) for a meta-analysis review], many studies, including the present, have not replicated this finding (e.g., Baribeau et al. 1987; Bauer 1997; Bauer et al. 1994a, 1994b; Polich and Bloom 1988; Polich et al. 1988; Hill et al. 1988). Some researchers have suggested that a "proper" family history should select subjects only from densely affected families, so as to minimize the prevalence of phenocopies. Unfortunately, when subjects are selected using this strategy, the resulting sample is likely to be confounded by high rates and severe forms of conduct disorder or ASPD (Bauer and Hesselbrock 1997). In the present study, and in numerous pre- vious studies, we have shown that there is no residual effect of either a family history of alcohol (Bauer 1997; Bauer et al. 1994a, 1994b; O'Connor et al. 1994) or drug (Bauer and Hesselbrock in press) dependence, or of familial density of alcohol or drug dependence (Bauer and Hesselbrock in press), when the confounding effects of conduct disorder/ASPD are taken into account.

Other data can be used to support the hypothesis that a family history of substance dependence is neither a necessary nor sufficient cause of P300 amplitude reductions. For example, it has long been known that P300 amplitude reductions are not specific to a family history of alcohol or drug dependence. Such reductions have been reported in the biological relatives of patients with schizophrenia or bipolar disorder (Blackwood et al. 1991; Friedman et al. 1995, 1982; Friedman and SquiresWheeler 1994; Kidogami et al. 1991; Roxborough et al. 1993; Squires-Wheeler et al. 1993) or Alzheimer's disease (Boutros et al. 1995). The similar P300 reductions found in the family members of schizophrenic, depressed, or bipolar patients and in the family members of drug and alcohol abusers is inconsistent with the different familial inheritance patterns of these disorders (Maier et al. 1993, Maier and Merikangas 1996; Kendler et al. 1995).

Furthermore, a recent publication from the Collaborative Study on the Genetics of Alcoholism (Bierut et al. 1998), and publications from other studies (Hill et al. 1977; Meller et al. 1988; Mirin et al. 1991; Rounsaville et al. 1991), have demonstrated independent inheritance of cocaine, opiate, marijuana, and/or nicotine dependence. Yet, the present study showed that P300 did not differentiate among three subtypes of familial substance dependence (cocaine, heroin, or alcohol). In conclusion, therefore, the popular notion that P300 amplitude reductions are specifically linked to familial substance dependence deserves to be questioned.

Despite the lack of evidence for an association between P300 and familial substance dependence, one should not conclude that P300 is uninformative for specifying and predicting risk. In numerous studies, P300 amplitude decrements have been associated with childhood conduct disorder and adult antisocial personality disorder. Both CD and ASPD are powerful predictors of the future development of a number of psychiatric disorders (Robins and Price 1991), including schizophrenia, depression, substance abuse, and bipolar disorder, among others. The P300 decrements linked to conduct disorder and ASPD are also significant predictors of relapse (cf. Bauer 1997). Accordingly, P300 can be highly informative in a number of contexts, despite its low specificity. Examples of potential applications include P300 as a tool for guiding case selection in biological or psychological interventions, for predicting treatment retention and/or resistance, and in the empirical validation of diagnostic subtypes (e.g., conduct 
disorder characterized by rules violation versus aggression or deceitfulness).

\section{ACKNOWLEDGMENTS}

This research was supported by Public Health Service Grants R01DA08598, P50AA03510, and R01DA05826.

\section{REFERENCES}

Baribeau JC, Ethier M, Braun C (1987): Neurophysiological assessment of selective attention in males at risk for alcoholism. In Johnson R, Rohrbaugh J, Parasuraman R (eds), Current Trends in Event Related Potential Research, EEG Supplement \#40. Amsterdam, Elsevier, pp 651-656

Bauer LO (1997): Frontal P300 decrements, childhood conduct disorder, family history, and the prediction of relapse among abstinent cocaine abusers. Drug Alcohol Depend 44:1-10

Bauer LO, Hesselbrock VM (in press): P300 decrements in conduct disorder in teenagers: Implications for substance abuse risk and brain development. Biol Psychiatry

Bauer LO, Hesselbrock VM (1997): Familial risk for alcoholism, conduct disorder symptoms, and gender: Effects on time estimation and slow potentials. Paper presented at the Annual Meeting of the Research Society on Alcoholism, San Francisco, CA

Bauer LO, Hesselbrock VM, O'Connor S, Roberts L (1994a): P300 differences between non-alcoholic young men at average and above average for alcoholism: Effects of distraction and past modality. Prog Neuropsychopharmacol Biol Psychiatry 18:263-277

Bauer LO, O'Connor S, Hesselbrock VM (1994b): Frontal P300 decrements in antisocial personal disorder. Alcohol Clin Exp Res 18:1300-1305

Begleiter H, Porjesz B, Bihari B, Kissin B (1984): Events related brain potentials in boys at risk for alcoholism. Science 225:1493-1496

Bench CJ (1993): Investigations of the functional anatomy of attention using the Stroop test. Neuropsychologia 9: 907-922

Bierut LJ, Dinwiddie SH, Beglieter H, Crowe RR, Hesselbrock VM, Nurnberger JI, Porjesz B, Schuckit MA, Reich T (1998): Familial transmission of substance dependence: Alcohol, marijuana, cocaine, and habitual smoking. Arch Gen Psychiatry 55:982-988

Blackwood DHR, St. Claire DM, Muir WJ, Duffy JC (1991): Auditory P300 and eye tracking dysfunction in schizophrenic pedigrees. Arch Gen Psychiatry 48:899-909

Boutros N, Woo SS, Tourello MW, Nasrallah HA, Burnes EM (1995): Evoked potentials in subjects at risk for Alzheimer's disease. Psychiatry Res 57:57-63

Bucholz KK, Cadoret R, Cloninger CR, Dinwiddie SH, Hesselbrock VM, Nurnberger JI, Reich T, Schmidt I, Sheckit MA (1994): A new semi-structured psychiatric inter- view for use in genetic linkage studies: A report on the reliability of the SSAGA. J Stud Alcohol 55:149-158

Christensen CA, Ford JM, Pfefferbaum A (1996): The effect of stimulus response incompatability on P3 latency depends on the task but not on age. Biol Psychol 44:121141

Duncan-Johnson CC, Kopell BS (1981): The Stroop effect: Brain potentials localize the source of interference. Science 214:938-940

Elmasian R, Neville H, Woods D, Schuckit M, Bloom FE (1982): Event related brain potentials are different in individuals at high and low risk for developing alcoholism. Proc Natl Acad Sci USA 79:7900-7903

Fergusson DM, Horwood LJ (1995): Predictability of categorically and dimensionally scored measures of disruptive childhood behaviors. J Am Acad Child Adolesc Psychiatry 34:477-485

Friedman D, Erlenmeyer-Kimling L, Squires-Wheeler E (1995): Subjects at risk for psychopathology from the New York high risk project: ERP's during adolescents have clinical outcomes in young adulthood. Electroencephalogr Clin Neurophysiology Suppl 44:379-386

Friedman D, Squires-Wheeler E (1994): Event related potentials as indicators of risk for schizophrenia. Schizophr Bull 20:63-74

Friedman D, Vaughan HG, Erlenmeyer-Kimling L (1982): Cognitive of brain potentials in children at risk for schizophrenia: Preliminary findings. Schizophr Bull 8:514-531

Gillen R, Hesselbrock VM (1992): Cognitive functioning, ASP, and family history of alcoholism in young men at risk for alcoholism. Alcohol Clin Exp Res 16:206-214

Herning RI, Hickey JE, Pickworth WB, Jaffe JH (1989): Auditory event related potentials in adolescents at risk for drug abuse. Biol Psychiatry 25:598-609

Hesselbrock VM, Bauer LO, Hesselbrock MN, Gillen R (1991): Neuropsychological factors in individuals at risk for alcoholism. In Galanter M (ed), Alcoholism: Children of Alcoholics, vol. 9. New York, Plenum Press, pp 21-41

Hesselbrock VM, Bauer LO, O'Connor S, Gillen R (1993): Reduced P300 amplitude in relation to a family history of alcoholism and antisocial personality disorder. Alcohol Alcohol (Suppl) 2:95-100

Hill SY, Cloninger CR, Ayre AB (1977): Independent familial transmission of alcoholism and opiate abuse. Alcohol Clin Exp Res 1:335-342

Hill SY, Steinhauer S, Zubin J, Baughman T (1988): Event related potentials as markers for alcoholism risk in high density families. Alcohol Clin Exper Res 12:545-554

Kendler KS, Walters EE, Neale MC, Kessler RC, Heath AC, Eaves LJ (1995): The structure of the genetic and environmental risk factors for six major psychiatric disorders in women: Phobia, generalized anxiety disorder, panic disorder, bulimia, major depression, and alcoholism. Arch Gen Psychiatry 52:374-385

Kidogami Y, Yoneda H, Esaba H, Sakai T (1991): P300 and first degree relatives of schizophrenics. Schizophr Res $6: 9-13$

Lahey BB, Hart EL, Pliszka S, Applegate B, McBurnett K 
(1993): Neuropsychological correlates of conduct disorder: A rationale and a review of research. J Clin Child Psychol 22:141-153

MacLeod CM (1991): Half a century of research on the Stroop effect: An integrated review. Psychol Bull 109:163-203

Maier W, Lichtermann D, Minges J, Hallmayer J, Heun R, Benkert O, Levinson DF (1993): Continuity and discontinuity of affective disorders and schizophrenia: Results of a controlled family study. Arch Gen Psychiatry 50:871-883

Maier W, Merikangas K (1996): Co-occurrence and cotransmission of affective disorders and alcoholism in families. Br J Psychiatry (Suppl) 30:93-100

Meller WH, Rinehart R, Cadoret RJ, Troughton E (1988): Specific familial transmission of substance abuse. Int J Addict 23:1029-1039

Mirin SM, Weiss RD, Griffin ML, Michael JL (1991): Psychopathology in drug abusers and their families. Compr Psychiatry 32:36-51

Moffitt TE (1993): The neuropsychology of conduct disorder. Dev Psychopathol 5:135-151

O'Connor S, Tasman A, Bauer LO, Hesselbrock VM (1994): Reduced P3 amplitudes of ERP's are associated with both a family history of alcoholism and antisocial personality disorder. Prog Neuropsychopharmacol Biol Psychiatry 18:1307-1321

Pardo JV, Pardo PJ, Janer KW, Raichle ME (1990): The anterior cingulate cortex mediates processing selection in the Stroop attentional conflict paradigm. Proc Natl Acad Sci USA 87:256-259

Pfefferbaum A, Christensen C, Ford JM, Kopell BS (1986): Apparent response incompatibility effects on P3 latency depend on the task. Electroencephalogr Clin Neurophysiol 64:424-437

Pickworth WS, Brown BS, Hickey JE, Muntaner C (1990): Effects of self reported drug use and antisocial behavior on evoked potentials in adolescents. Drug Alcohol Depend 25:105-110

Polich J, Bloom FE (1988): Event related brain potentials in individuals at high and low risk for developing alcoholism: Failure to replicate. Alcohol Clin Exp Res 12:368-373

Polich J, Haier R, Buchsbaum M, Bloom FE (1988): Assessment of young men at risk for alcoholism with P300 from a visual discrimination task. J Stud Alcohol 49: 186-190

Polich J, Pollock VE, Bloom FE (1994): Meta-analysis of P300 for males at risk for alcoholism. Psychol Bull 115:55-73
Posner MI, Driver J (1992): The neurobiology of selective attention. Curr Opin Neurobiol 2:165-169

Renault B, Fiori N, Giami S (1988): Latencies of event related potentials as a tool for studying motor processing organization. Biol Psychol 26:217-230

Rice JP, Reich T, Bucholz AK, Neuman RJ, Fishman R, Rochberg N, Hesselbrock VM, Nurnberger JI, Schuckit MA, Begleiter H (1995): Comparison of direct interview and family history diagnoses of alcohol dependence. Alcohol Clin Exp Res 19:1018-1023

Robins LM, Price RK (1991): Adult disorders predicted by childhood conduct problems: Results from the NI Match Epidemiological catch area project. Psychiatry 54:116-125

Rounsaville BJ, Kosten TR, Weissman MM, Prusoff B, Pauls D, Anton SF, Merikangas K (1991): Psychiatric disorders in relatives of probands with opiate addiction. Arch Gen Psychiatry 48:33-42

Roxborough H, Walker MT, Muir WJ, Blackburn JM, Blackwood DH (1993): Neuropsychological and P300 abnormalities in schizophrenics and their relatives. Psychol Med 23:305-314

Semlitsch HV, Anderer P, Schuster P, Presslich O (1986): A solution for reliable and valid reduction of ocular artifacts, applied to the P300 ERP. Psychophysiology 23: 695-703

Siegrist M (1997): Test-retest reliability of different versions of the Stroop test. J Psychol 131:299-306

Siegrist M (1995): Reliability of the Stroop test with single stimulus presentation. Percept Mot Skills 81:1295-1298

Slutske WS, Heath AC, Dinwiddie SH, Madden PA, Bucholz KK, Dunne MP, Statham DJ, Martin NG (1997): Modeling genetic and environmental influences in the etiology of conduct disorder: A study of 2682 twin pairs. J Abnormal Psychol 106:266-279

Squires-Wheeler E, Friedman D, Skodol A, Erlinmeyer-Kimling L (1993): A longitudinal study relating to P3 amplitude to schizophrenia spectrum disorders and to global personality functioning. Biol Psychiatry 33:774-785

Stroop JR (1935): Studies of interference in serial verbal reactions. J Exp Psychol 18:643-662

Valle-Inclán F (1996): The locus of interference in the Simon effect: An ERP study. Biol Psychol 43:147-162

Whipple SC, Parker ES, Noble EP (1988): A atypical neurocognitive profile in alcoholic fathers and their sons. J Stud Alcohol 49:240-244 